\title{
"We Are Not in the Least Bit Used to These Ways of Studying": Developing Academic Competence in All Students
}

\author{
Wendy J. McMillan, D.Ed. \\ Abstract: This article is located in the field of academic development in oral health science education. Specifically, it examines \\ the academic difficulties experienced by oral hygiene students in their transition from high school to university. A qualitative \\ approach was employed to elicit student and lecturer perceptions. Drawing on empirical evidence from a case study of a cohort of \\ first-year oral hygiene students at a dental faculty in South Africa, the article contributes to an understanding of how first-year \\ university students might be better prepared for the challenges of reading and writing in higher education. The voices of lecturers \\ and students are used to highlight the nature of the difficulties that students experience in the transition from high school to \\ university. The suggestions that students made regarding how the transition might be eased are also examined. The final section \\ draws on these suggestions and presents a working model for an academic development module for first-year oral health \\ students.
}

Dr. McMillan is Education Advisor, Faculty of Dentistry, University of the Western Cape, South Africa. Direct correspondence and requests for reprints to her at Faculty of Dentistry, University of the Western Cape, Private Bag X17, Mitchells Plain, 7785, Cape Town, South Africa; 27-21-937-3084 phone; 27-21-683-2909 fax; wmcmillan@uwc.ac.za.

Key words: oral health science education, transition to university, academic development

Submitted for publication 1/13/05; accepted 7/6/05

"T here are words that I have never heard in my life and then you must take extra time because you must look it up and you must understand what the word means before you can go on and learn anything further." "The lecturers ... forget that we have just come out of school and we are not in the least bit used to these ways of studying." "Here (there) is a lot of work and you have to make notes for yourself . . . and you have to do everything for yourself." "At school the teacher showed you more. If you could not understand, the teacher would come to you and ask, 'Do you understand?' University is different; you have to be more responsible to go to the lecturer if you don't understand something." These are the voices of first-year oral hygiene students at a South African university. Their testimony illustrates the difficulties with regard to academic competence that these young people experience in their transition from high school to university. Their testimony is not unique to the South African context. ${ }^{1-5}$ Yet, while there is a growing awareness of the transition difficulties that students experience, academic literacy programs tend to be interventionist, designed to address "special needs" cases (for example, older entry students, ${ }^{6}$ working class students, ${ }^{4,6}$ or students whose home language is not the language of instruction ${ }^{4}$ ). Little research has been done to outline the academic literacy needs of a full spectrum of first-year university students or to design academic development initiatives that are fully integrated into professional education curricula.

Drawing on empirical evidence from a cohort of first-year oral hygiene students at a dental faculty in South Africa, this article contributes to an understanding of how undergraduate students might be better prepared for the academic challenges at university. Although located within the field of oral hygiene education, the study has further relevance for health education programs that admit students directly from high school or that enroll large numbers of students who do not have well-developed skills in the language of instruction. The voices of oral hygiene lecturers and students serve as a case study, highlighting the nature of the transition difficulties, as well as providing suggestions of how to address them.

The first section of the article discusses the context from which the data was gathered. Two different aspects are presented as shaping this context: challenges resulting from the transition from generalist high school education to specific professional education at university, and specific needs of students for whom English as a second language or inequalities in secondary education presented barriers to learning. The second section enumerates the methodology used for the study, highlighting the way in which a case study approach allows portrayal, analy- 
sis, and interpretation of the uniqueness of real individuals and situations through accessible accounts. ${ }^{7}$ The potential for generalization from an appropriate case study is discussed. The article then sets out to locate the study within the relevant literature and examines specifically the transition of school learners to higher education. The focus on transition is contextualized by focusing on discipline-specific concepts and language, as well as through an examination of learning in a second language. The fourth section presents the voices of the first-year oral hygiene students and their lecturers. Their accounts are used to highlight the nature of the transition difficulties, as well as to formulate suggestions regarding how to remedy them. The final section draws on these suggestions and presents a working model for an academic development intervention. The potential transferability of this model is briefly highlighted.

\section{The Research Site}

The focus for this article - to contribute to an understanding of how students might be better prepared for the academic challenges of universitywas stimulated by two sets of concerns regarding first-year oral hygiene students in a dental faculty at a South African university. The first concern related to the well-documented needs of students as they make the transition between school and university. ${ }^{1-5}$ Most students struggle with the transition from the nurturing environment of high school to the context of greater responsibility and personal challenge at university. At university, usually for the first time, students are faced with field-specific discourse and are required to take an active role from within this new discourse. ${ }^{8}$ Dison and Rule ${ }^{9}$ provide a metaphor for understanding what discourse is and how it operates. They suggest that a discipline might be understood as a subculture. Its discourse is made up of codes (linguistic, intuitive, creative, etc.), conventions (essay structure, research, referencing, reporting, etc.), concepts (main ideas and debates in the discipline, etc.), values (what qualifies as knowledge or evidence, and caring, etc.), canons (primary texts and theories/authorities, etc.), and skills (both cognitive and linguistic) in order to operationalize the foregoing. On entering a new discipline, as Hutchings ${ }^{10}$ points out, students need to learn about and acquire adequately the discourses for future success within the discipline. The rules by which competencies in these new fields are assessed are seldom made overt, which adds to the general confusion experienced by learners new to higher education. ${ }^{11}$ It was argued in the dental faculty that a learning program, designed to develop the academic skills specific to both higher education and health sciences education, needed to be put in place.

The second concern related only to some of the students in the oral hygiene department. It centered on the high failure rates of working class African students in this department. These students came from ex-Department of Education and Training (DET) schools. Schooling provision was segregated during the apartheid era, and schools for African learners, managed by the DET, were by far the worst provisioned. ${ }^{12}$ While the DET no longer exists, its effects and the legacy of segregated and unequal provision of buildings, materials, and teacher education are likely to be felt for a long time. In consequence, the majority of black working class students continue to be schooled in print-impoverished environments, often characterized by teacher-centered, predominantly oral, classroom cultures. ${ }^{13}$

The ex-DET African students entering the dental faculty are further disadvantaged by their lack of competence in English, the language of instruction at the university. First, they do not have the language of instruction as a home language. Second, although official policy is that the medium of instruction in exDET schools is English, the realities of the legacy of apartheid schooling mean that most working class African students have English only as an additional language and their competence in the language is frequently poor. Thus while all students might be expected to experience transition difficulties between high school and university, the experiences of African working class students were exacerbated.

The intention of the research was to inform academic literacy skills development for first-year oral hygiene students. Findings, as presented here, might support the development of other health sciences education academic literacy programs. Such programs might service all students in their transition to university, as well as support those who experience inequalities in high school education and the language of instruction as a second language.

\section{Research Methodology}

In setting out to examine the disparity between the academic skills that students bring to university and the competencies that universities expect, the 
study investigated the nature of the school-university transition and explored how the transition might better be facilitated. A qualitative research approach was used. Qualitative research differs from a quantitative approach in a number of ways. Qualitative research is concerned with how the social world is interpreted, understood, experienced, produced, and constituted. ${ }^{14}$ It sets out to generate a "close-up, detailed or meticulous view" of the particular contexts or phenomenon involved. Qualitative research is based on methods of data generation that are both flexible and sensitive to the social context in which data are produced - rather than being rigidly standardized or structured. Qualitative research aims to produce rounded and contextual understandings on the basis of rich, nuanced, and detailed data. Methods of analysis, explanation, and argument-building involve understandings of complexity, detail, and context. There is more emphasis on holistic forms of analysis and explanation than on charting patterns, trends, and correlations.

The findings presented here draw on a case study conducted with a cohort of first-year oral hygiene students and their lecturers. A case study is a specific instance frequently designed to illustrate a more general principle. ${ }^{15}$ The single instance is of a bounded system and provides a unique example of real people in real situations. ${ }^{7}$ Case study, as a sampling approach, makes possible a depth of insight not always achievable through numerical analysis. ${ }^{7}$ Focusing on specific issues, processes, or phenomena, an in-depth case study with a limited cohort is about depth, nuance, and complexity and understandings of how these work. ${ }^{14}$ The aim is to produce, through sampling, a relevant range of contexts or phenomenon, strategic, and possibly cross-contextual comparisons. ${ }^{14}$ The sample is designed to encapsulate a relevant range of experiences, characteristics, processes, types, categories, or cases in relation to the wider universe, but not to represent it directly.

There were twenty-six students in the first-year oral hygiene class in 2004. Six students were excluded from the research cohort since it was felt that they were not "typical" first-year students coming straight from secondary to higher education. They had already completed a university degree or technikon diploma or had completed their schooling more than three years prior to the research study. Two students elected not to participate in the research, and three did not return their consent forms. The cohort consisted of the remaining fifteen students. Six were interviewed one-on-one using a semi-struc- tured protocol, and open-ended questionnaires were distributed to the remaining nine students.

Students participated in ten subjects or modules in the first academic year. Two of these modules were taught by panels of lecturers, and it was not considered appropriate to elicit the insights of staff members who had only a lecture or two with the cohort class. Ten lecturers taught the remaining eight modules. Three of these lecturers were interviewed, one-on-one, using a semi-structured protocol. Open-ended questionnaires were distributed to the remaining seven lecturers.

The data collection took place six months into the first academic year, just before the students wrote their midyear examinations.

Ensuring validity of research findings presents a particular challenge in the context of qualitative research. External validity refers to the degree to which the results can be generalized to the wider population, cases, or situations. Generalizability in qualitative research is interpreted as comparability and transferability. ${ }^{16}$ It is possible, Eisenhart and Howe ${ }^{16}$ argue, to assess the typicality of a situation (the participants and settings) so as to identify possible comparison groups and to indicate how data might translate into different settings and cultures. Schonfield ${ }^{17}$ argues that it is important in qualitative research to provide a clear, detailed, and in-depth description so that others can decide the extent to which findings from one piece of research are generalizable to another situation. To this end, "thick description"18 of the students' and their lecturers' lived experiences and feelings about academic needs in the transition from high school to university have been provided in this article. Thick description, according to Cohen, Manion, and Morrison, ${ }^{7}$ strives to "view situations through the eyes of participants, to catch their intentionality and their interpretations of frequently complex situations, their meaning systems and the dynamics of the interaction as it unfolds."

\section{The Transition to Higher Education}

Scott ${ }^{19}$ argues that the main problem that school leavers experience in the transition to university is the gap between what is expected at school and what is expected at university. Drawing on studies in six countries (Germany, France, Britain, Kenya, South Africa, 
and China), Foster and Russell ${ }^{11}$ suggest that these gaps are multiple — social, cultural, and academic:

students from most educational systems must adapt to major challenges as writers when they enter university studies. They must inhabit new institutional and material spaces, negotiate the intimidating texts and sometimes incomprehensible lectures couched in new terminologies, and adapt to the dangerous freedoms of unstructured work time. (p. 22)

Thus, while simultaneously "leaving a more nurturing environment in secondary school and entering an environment of greater responsibility and greater personal challenge," 11 students are faced with specific academic challenges, especially with regard to academic writing. Writing is significant, first, because of the role it plays in supporting learning; second, because it is often a key vehicle for assessment; and third, because it is in dealing with student writing that academics are confronted with students' learning difficulties and thus the problems that academic development sets out to address. ${ }^{20}$ Foster and Russell ${ }^{11}$ argue that the transition to university, and the demands on academic writing competencies in that context, involves negotiating identity and authority in the intersection of what students bring from schooling and what universities expect from them. According to Moore, ${ }^{20}$ learners need some sense of the requirements of their audience, of the purpose of the text, and of their identity as writers. All of these shape the decisions writers must make in selecting and arranging their ideas, how they frame these in language, and the authoritative relations they attempt to constitute in their texts.

The expectations implied in the genres and activities of secondary school writing are frequently challenged at university by a set of expectations different from the genres and activities of disciplinary discourse. ${ }^{11}$ Students struggle to move away from the single truth espoused in textbook accounts. Tertiary students are expected to enter into the debate and demonstrate the ability to draw on a number of competing, and often contesting, viewpoints in order to position themselves within the debate. ${ }^{5,8,21}$ Students must decide, as Foster and Russell ${ }^{11}$ put it, "if they want to be one of the people who write in these new and as yet unfamiliar ways." The price of failing to comply with the new identity is academic failure.

This difficulty is exacerbated for working class African students in the South African context. In most
ex-DET schools, an apartheid legacy of large classes, underprepared teachers, and lack of adequate materials have produced a tradition of textbook-based lecture and recitation with little extended writing. ${ }^{13,22,23}$ The writing that does occur is mainly "single-truth" accounts of textbook knowledge. ${ }^{11}$ These students are frequently ill-equipped to engage with writing tasks that require positioning within unfamiliar discourses.

The transition to university for all students is further complicated by demands that students master discourse specific to their field of professional study. ${ }^{8}$ This is specifically so in the field of health sciences where "linguistic shortcuts ... refer to various theories and sets of assumptions that have been commonly established by the disciplinary insiders." Discourses differ across disciplines, and as Hutchings ${ }^{10}$ highlights, even across subjects within the same discipline. She notes also that different genres exist within the same discourse, citing in the health sciences context how a clinical report requires a different style of writing from an essay for health and society or an anatomy report. ${ }^{10}$

Further, when students arrive at university, they frequently also encounter new disciplinary epistemologies (or knowledge frameworks for understanding the world) that govern how thoughts and opinions may be conceptualized and expressed, ${ }^{11}$ and they are required to write from within these new disciplinary parameters. As Dison and Rule ${ }^{9}$ explain:

At university students are encouraged to
question received viewpoints and to develop
their own intellectual positions rather than
to mimic authoritative voices. However, if
they do not defer to these authorities, if they
merely draw on their own experiences in
their own registers, they will also fail. In
order to succeed, the student has to encode
her own insights and experiences into dis-
courses of the discipline, often without much
idea of the underlying values and epistemic
structures which shape the discipline. (p. 87)

On entering a new discipline, like oral hygiene, it is necessary for students to learn about and acquire competence in the discourses if they are to experience future success within that discipline.

While this is a challenge for all students entering university for the first time, it is particularly difficult for students who are not competent in the language of instruction. Although the official policy regarding medium of instruction in ex-DET schools 
in South Africa is through English, the reality is that most working class African students have English only as an additional language and their competence to use the language for conceptual thinking is frequently poor. ${ }^{22}$ The added dimension of understanding, acquiring, and manipulating discipline-specific discourse when a student's language of instruction competence is already compromised serves as a severe challenge for many working class African students.

Foster and Russell ${ }^{11}$ highlight a further constraint to first-year students gaining competence in the new discipline-specific discourses and epistemologies. Lecturers, they argue, seldom make explicit either their expectations or the rules by which students are expected to think, write, and perform academic tasks at university. Foster and Russell highlight that higher education lecturers commonly presume that writing is a basic skill that students should have learned earlier in primary school and that any improvement in writing competencies - even in specific discourses or disciplines - is the responsibility of the university's English department or remedial Academic Development personnel. Lave and Wenger $^{24}$ contest this commonplace assumption. They argue instead that learning and writing strategies do not develop independently, rather that their development is holistic: that "activities, tasks, functions, and understandings do not exist in isolation; they are part of broader systems of relations in which they have meaning."

Moore et al. ${ }^{25}$ argue further that literacy practices acquired in one context may be less transferable to other contexts than was previously assumed. They suggest therefore that school-based literacies may be inadequate preparation for university. Moore et al. call for explicit teaching of the discourses and genres of academic disciplines so that students who find them alien can gain access to them and have more chance of success. Moore ${ }^{20}$ elaborates on this position. He argues that university educators need to pay greater attention to the opportunities that they provide for students to grapple explicitly with the language of the discipline. For this, he suggests an apprenticeship model:

This includes active approaches to reading, listening and discussion of concepts, an apprenticeship to both the concepts and the language by which they are constituted.... The various forms of writing (or genres) common to a discipline need to be modeled and understood for how they convey mean- ing to different audiences for different purposes. (p. 86)

How might this be achieved? In the section that follows, the opinions of oral hygiene staff and students are canvassed.

\section{Experiencing the Transition from School to University}

All students indicated that the transition from school to university had presented some difficulty. Their expressed difficulties were echoed by academic staff. An analysis of these difficulties has the potential to inform remedial action that might ease students more effortlessly into the demands of higher education. In the discussion that follows, these identified difficulties, and the advice that students gave regarding what should be included in an academic development program, are considered.

Two themes emerged regarding the transition from school to university: language and academic competencies.

\section{Language}

Many students commented on language-related difficulties. These were not all ex-DET students. However, their common experience was that none had English, the language of instruction, as a home language. They explained how they were struggling at university: "there is a problem, because my home language is Afrikaans and because I received my [school] instruction in Afrikaans." An ex-DET student who did not have English as a home language echoed this position, implying that the inability to learn in her home language was negatively affecting her performance: "like in high school ... when they teach us something, they also translated into Xhosa [the student's home language] so we can better understand it." Central was the assumption that competence in English was a precursor to successful academic performance: "At [this university] . . . your English must be good, [you need] a good vocabulary to understand and interpret English well."

For many of these students, poor skills in the language of instruction complicated mastery of discipline-specific discourse. As one student put it, "There are some English words that I have a problem with - the terminology . . . the vocabulary itself." Another student explicitly located the differ- 
ence between school and university in the nature of subject-specific discourse:

I think it is the vocabulary that differs a lot. There are words that I have never heard in my life and then you must take extra time because you must look it up and you must understand what the word means before you can go on and learn anything further.

For at least one student, failing to master the discourse appeared to jeopardize her successful academic performance:

So they [lecturers] must make simple language - the words easier for other people. . . . Some of them, they use terminology. There is a term there, and there is a term in the sentence ... following the term. And you don't know if it is the right answer ... because ... in the sentence they use a term so you are not sure if it is the right answer. ... You will know the answer but you are not sure if the answer is right for that question because of that word.

Student difficulties with discourse were also highlighted by lecturers: "language - not understanding, or finding dental/scientific terminology difficult." One staff member, who taught oral biology, a discipline within the field of oral hygiene, summed up the difficulty of subject-specific discourse for students whose home language is not the language of instruction: "It is like three new languages that they must learn." By this he meant that many students had the triple challenge of being unfamiliar with the language of instruction, with the language of oral health, and specifically with the language of oral biology.

While the language policy of an institution can only be negotiated at the management level, facilitating learning through discipline-specific discourse can, and should, be within the domain of subject lecturers and academic support personnel. Greater attention should be paid to the opportunities that are provided for students explicitly to grapple with the language of the discipline. This includes active approaches to reading, listening, and discussion of concepts - "an apprenticeship to both the concepts and the language in which they are constituted." 20 According to Moore, ${ }^{20}$ students engaging with the "new language" of a discipline need opportunities to present concepts in oral and written dialogues with their lecturers. This stands in contrast to the normal practice by which a student hands in a piece of writing in the knowledge that it will be graded, rather than responded to in more naturally communicative ways. Such interventions would benefit not only those students whose home language differs from that of the classroom. English-speaking students - for whom the discipline discourse is a "new language"would also benefit.

\section{Academic Development}

The majority of the difficulties that students experienced were located in the field of academic skills. Most students noted that they had had little experience, prior to coming to university, of projects or essay writing - the two assessment strategies most prevalent in the oral hygiene department. Typical responses were "We did not get a lot of projects at school" or "Not so much research essays." One student presented the difficulty as a dual problem: not knowing how to write in the manner expected at university and not knowing why her response was incorrect:

I still don't know how to write essays. I struggle a lot with that. I had an essay ... and I researched a lot on it . . . and I got $30 \%$ for it and I read it, and I don't know what went wrong. So I think I don't really know how to do it.

This lack of experience was echoed in the comments that lecturers made regarding the academic writing shortcomings of first-year students. According to lecturers, students had difficulty "approaching an assignment" and "solving a problem logically." They didn't know "what information is relevant and irrelevant." Many students, lecturers said, struggled to "express themselves in sentences and readable language." One lecturer described the problems at length: "there is no logic in what they say. They don't worry about putting things into paragraphs, there is no introduction, there is no conclusion." Other lecturers commented on the sub-skills that first-year students still needed in order to be successful in academic writing, "how to summarize articles, paragraphs."

These difficulties could effectively be addressed in an academic literacy module that expressly teaches the skills prerequisite for successful academic writing. One student, explaining where she needed help to be academically competent at university, used an apprenticeship model to describe how this might be achieved: 
They can help me with skills like computer skills and also reading and writing skills. That [academic literacy] course is [a] right [idea], but I [as teacher] can also give them the chance to write . . . so that I can see ... who is struggling with the language, the writing and help them.

Moore's ${ }^{20}$ position that academic skills should be embedded in real writing opportunities suggests that any such intervention should draw on the discourse of the oral health disciplines that these students are studying and should be embedded in preclinical and clinical subjects.

A second cluster of academic skills centered on the need for first-year students to become independent learners. Many students described school as a "spoon-feeding" environment: "At school you are spoon-fed. They give you questions and answers. The level of education is different at school." While students acknowledged that university should be different, they struggled to understand what exactly they needed to do in order to become more independent learners. One student, discussing the transition to university, explained, "More work-in the sense that - I can't quite . . . I understand that it can't be the same as school, but we didn't really have projects so...."

Students described how the university system assumed that students had the skills in place in order to be independent learners, for example, library research skills and note taking. One student described his experiences of self-study. It is implicit in the student's testimony that he was not sure if he was doing the task correctly:

The lecturer, he gives the work to you and you must afterwards, naturally, do research in order to stay up to date . . . in the sense that you must, after class, go to the library and find out for yourself, to try and understand for yourself.

This situation was exacerbated for those students who had come from schools in working class communities. Many of those students had not had libraries at their schools and were consequently ignorant of the basic skills required to locate materials in a library.

Other students explained how note-taking was a new skill and described the difficulties that they experienced: "Here it is a lot of work and you have to make notes for yourself and you have to do every- thing for yourself." For others, independent study and note taking were described as an embedded challenge. One student explained the difficulties that she experienced learning the skill while simultaneously having to master the subject content: "Like sometimes they [lecturers] just come in, put their transparency on the projector and just . . talk-like go over and we don't get a chance to write, and they just say now we have to go to the library and get the book. . . . Sometimes it is not easy to learn that subject and we don't even understand what is going on."

Lecturers appeared to be less aware of the challenges that independent learning made to students, although there were comments that students lacked skills for "taking notes."

A third set of problems related to the difficulty that students had answering assignment and test questions at university. This problem did not appear to be related to language fluency or discourse. It was more specifically related to how questions in higher education are phrased and the depth that is required. One student explained her struggle:

Some of the subjects I can study very hard and the questions will just come in a different way, but knowing that this is the answer. But you are not sure it is the right question or what. Then you tend to write the wrong answer and you are supposed to write the answer you had in mind. But you write the answer and then she wants it in another way, but it is right, but she wants it in another way. So that means that you are wrong.

Another student articulated her perception of what was required in order to answer questions successfully. Her answer signals how students experience the disparity between school and university:

University's tasks, they look for more information-you must go more deeply into it to get something. They are not looking for superficial because then you don't get marks. They mark unbelievably strictly. ... At school, you just had to sound like you know what you're talking about and then you got a mark. Here you have to say outright what you mean; otherwise, you don't get marks.

Most lecturers noted that students struggled "to understand the questions that they are being asked in class and their class tests and assignments." As one lecturer put it, "Then when I finally read the work 
and I see it does not make sense. They didn't understand the question."

There are a number of strategies that first-year students might be taught regarding debriefing questions. These include analyzing what action the verb that introduces the question indicates - for example, understanding the difference required when asked to "list" something or when required to "compare" something. Similarly students can be taught a three point strategy for interpreting questions. These tools might be taught in an academic literacy module. One student wrote in detail how this might be achieved:

Give them [students] lectures of how to read and answer questions, e.g., Describe, Explain, Name things. Show them how to break up questions. Tell them/explain the words being used. There should at least be 1 or 2 of these lectures a week. Lecturers should tell students or give them examples [of what] they expect for answers.

Finally, many students indicated that they practiced learning strategies that were inadequate for university. Some of these students appeared unaware that these strategies were unsuitable for the conceptual learning required by higher education:

When I was like studying, I study there, I read my stuff and I write it. I rewrite it again with my head and if I don't know I just go through it again and write it again. Any missing word or sentence, I just rewrite it.

Others indicated that they were aware of the shortcomings of rote learning but had no alternative strategies with which to replace it:

At the moment I have a problem because you must understand things first. If you don't understand something you can't memorize it because if you understand it, you can lay it out better, and maybe write down in your own words.

Even students who did not expressly rely on rote learning argued that they needed help with study skills:

I think what we all need is the way in which to answer your exam papers because everybody does it in a way that he thinks is right but it is not necessarily what is expected of you and then you come and you think you are doing well, and you write and you go on and then you are disappointed because it is not what you expected. And it is all about you answering your questionnaire incorrectly or something.

Many lecturers echoed an awareness of the difficulties that these students had. Most frequently this was expressed by lecturers as the fact that students had "no or little acquaintance with study methods."

Like the various other academic shortcomings indicated in this section, study skills are easily taught. A number of students were aware of the need for these skills. One student explained in her questionnaire that she needed "lectures on how to study, how to prepare for exams and tests 'cause it [is] what I'm struggling about at the moment." Explicit teaching, embedded in the discourse and the epistemological assumptions of particular oral health disciplines, would maximize the benefit to students. One student, describing what she had found to be effective at university, indicated some of the strategies that might benefit all students:

I read through it maybe once or twice, and then make a mindmap, depending on what subject it is. . . If I had something like science, if the main topic is like chemistry, then I do spider diagrams and then I split up maybe into experiments or theory and link them up - maybe with colors.

This section has highlighted a number of academic competencies that are prerequisite if students are to make a successful transition from school to university. These competencies will be discussed in detail in the section that follows.

\section{Designing a "Transition to University" Intervention}

The testimony of oral hygiene staff and students has highlighted the academic needs of these young people in their transition from school to university. The significance of the highlighted competencies in initial academic success at university has been substantiated by the literature. These competencies can be summarized in the following list:

- deconstruction of the discourses and epistemologies specific to the oral health field

- academic writing skills, including

—understanding an essay question

- locating information in the library (books and journals) 
-locating information electronically (websites, electronic journals)

- selecting appropriate resources

- evaluating the significance, appropriateness, and reliability of resources

- extracting information from text

- note-taking (in this context)

- collating information from a variety of texts

- planning a logical flow to an academic essay

- using information to present an argument

—writing an academic essay

- recognizing what tone is appropriate for which genre of academic writing (for example, essay, case report)

—using an academically appropriate tone

- referencing correctly in an academic essay

- compiling a bibliography/list of references correctly

- recognizing when an essay has attained an academically appropriate standard and when it falls short

-editing and critically rewriting an essay until it is of an appropriate academic standard

- independent learning skills, including

-note-taking in lectures

- locating relevant further reading in both the library and electronically

-note-taking skills appropriate for the above further reading activities

- strategies to seek assistance from peers and academic staff

- examination and test strategies, including

- understanding the meaning of an assessment question

— answering specifically what is asked by the question

- responding appropriately (for example, the difference between "list" and "discuss")

- time management in a test/examination context

- study skills, including

-identifying key concepts (to prevent simplistic rote-learning)

- strategies for summarizing and organizing information

-note-taking specific to study and revision (for example, spider diagrams, mindmaps).

The literature ${ }^{20,24,25}$ indicates that the teaching of these competencies should be embedded in discipline-specific contexts. Ideally, every lecturer should embed the teaching, practicing, and testing of these skills in every discipline or subject. Currently, such a vision may not be realistic without extensive staff development. In the interim, a free-standing module or academic literacy subject dedicated to the development of academic literacy skills could, and should, develop these competencies. Discipline-specific content from the field in which students are studying can be used as a relevant and embedded learning context. One such opportunity, developed for the oral hygiene department cited in this article, is presented here.

In a ten credit (100 hour) module dedicated to academic literacy, first-year oral hygiene students will be required (amongst a number of other embedded academic literacy tasks) to write an academic essay on "What are caries?" The topic has been chosen so as to integrate holistically with the core oral hygiene subject, Clinical Practice. Such a strategy, it is hoped, will ensure transferability of academic skills from the stand-alone academic literacy intervention into all the preclinical and clinical subjects of the oral hygiene teaching program.

Initial sessions, drawing specifically on the set essay topic, are planned to develop in students the skills to recognize the difference between popular and academic styles of writing, to deconstruct an essay question, and to access and select appropriate resources from library and electronic media. Resources will be brought into class, and strategies for evaluating the relevance, appropriateness, and reliability of these materials will be modeled by lecturers and practiced by students. Further sessions will focus, using similar methodologies, on note-taking from resources, synthesizing an argument, organizing a logical argument, strategies for editing, writing references, and compiling a bibliography correctly. Finally, students will develop rubrics to assess whether a piece of writing meets the criteria for success in the genre of academic writing in the oral health sciences. They will assess their own writing and that of a peer against these criteria. Feedback from this formative assessment will be used by them to compile a final draft of their essay. This version will be submitted for summative assessment.

Such a module has wider applicability. The literature $^{1-5}$ indicates that an academic literacy intervention has relevance for all students since first-year students are encountering, for the first time, new, field-specific discourses. All students therefore need initiation into discipline-specific discourse. Furthermore, it is arguable that such interventions have the potential to add further value to the learning of students who come from less university-oriented environments where resources may be inadequate or teachers underqualified. ${ }^{8,12,13,20,22}$ 


\section{Acknowledgments}

The author would like to thank all those oral hygiene students and lecturers who so willingly and honestly shared their views and perspectives on the needs of first-year students.

\section{REFERENCES}

1. Parshotam K. Transition into HE: the first year as a critical experience. Conference Proceedings, SAADA Conference, Port Elizabeth, South Africa, December 2-4, 2004.

2. Schoeman A. Bridging the gap: fact or fiction? The effectiveness of the academic introductory programme as an academic development strategy for first-year BA students at the university of Stellenbosch. Conference Proceedings, SAADA Conference, Port Elizabeth, South Africa, December 2-4, 2004.

3. Foster D, Russell D, eds. Writing and learning in crossnational perspective: transitions from secondary to higher education. Chicago: National Council of Teachers of English, 2002.

4. Angelil-Carter S, ed. Access to success: literacy in academic contexts. Cape Town: UCT Press, 1998.

5. Ferreira J. Transition from school to university. South African J Higher Educ 1995;9:154-8.

6. Ivanic R. Writing and identity: the discoursal construction of identity in academic writing. Amsterdam: Johan Benjamin, 1998.

7. Cohen L, Manion L, Morrison K. Research methods in education. London: Routledge, 2001.

8. Shay S, Moore R. Roles under construction: the intersection of writer agency and task design in South Africa. In: Foster D, Russell D, eds. Writing and learning in crossnational perspective: transitions from secondary to higher education. Chicago: National Council of Teachers of English, 2002.

9. Dison L, Rule P. Bridging the subject-students divide: an integrated approach to developing foundational curricula. Acad Dev 1996;2(2):83-97.

10. Hutchings $C$. Transitional barriers and contextual gaps in an academic department. In: Angelil-Carter S, ed. Access to success: literacy in academic contexts. Cape Town: UCT Press, 1998.

11. Foster D, Russell D. Introduction: rearticulating articulation. In: Foster D, Russell D, eds. Writing and learning in cross-national perspective: transitions from secondary to higher education. Chicago: National Council of Teachers of English, 2002.

12. Thesen L. Voices, discourse, and transition: in search of new categories in EAP. TESOL Q 1997;31(3):487-511.

13. Kapp R, Bongani, B. "I was just never exposed to this argument thing": using a genre approach to teach academic writing to ESL students in the Humanities. Paper presented at the SAADA conference, Cape Town, South Africa, December 3-5, 2003.

14. Mason J. Qualitative researching. London: Sage, 2002.

15. Nisbet J, Watt J. Case study. In: Bell J, Bush T, Fox A, Goodey J, Goulding S, eds. Conducting small-scale investigations in educational management. London: Harper and Row, 1984.

16. Eisenhart M, Howe K. Validity in educational research. In: LeCompte M, Millroy W, Preissle J, ed. The handbook of qualitative studies in education. New York: Academic Press, 1992.

17. Schonfield J. Increasing the generalizability of qualitative research. In: Hamersley M, ed. Social research: philosophy, politics and practice. London: Sage, 1993.

18. Geertz C. Thick description: towards an interpretive theory of culture. In: Geertz C, ed. The interpretation of cultures. New York: Basic Books, 1973.

19. Scott M. Cracking the codes anew: writing about literature in England. In: Foster D, Russell, D, eds. Writing and learning in cross-national perspective: transitions from secondary to higher education. Chicago: National Council of Teachers of English, 2002.

20. Moore R. How science educators construe student writing. In: Angelil-Carter S, ed. Access to success: literacy in academic contexts. Cape Town: UCT Press, 1998.

21. Li X. "Tracking (dis)connecting": Chinese high school and university writing in a time of change. In: Foster D, Russell D, eds. Writing and learning in cross-national perspective: transitions from secondary to higher education. Chicago: National Council of Teachers of English, 2002.

22. Kapp R. Language, culture and politics. In: Angelil-Carter $\mathrm{S}$, ed. Access to success: literacy in academic contexts. Cape Town: UCT Press, 1998.

23. Gough D. Myths of multiculturalism: demography and democracy. Bua! 1994;9(3):9-11.

24. Lave J, Wenger E. Situated learning: peripheral participation. Cambridge: Cambridge University Press, 1991.

25. Moore R, Paxton M, Scott I, Thesen L. Retrospective: language development initiatives and their policy contexts. In: Angelil-Carter S, ed. Access to success: literacy in academic contexts. Cape Town: UCT Press, 1998. 